\title{
On ceteris paribus laws in economics (and elsewhere): why do social sciences matter to each other?
}

\author{
MENNO ROL \\ University of Groningen \\ University of Twente
}

\begin{abstract}
Stipulating universal propositions with a ceteris paribus clause is normal practice in science and especially in economics. Yet there are several problems associated with the use of ceteris paribus clauses in theorising and in policy matters. This paper first investigates three questions: how can ceteris paribus clauses be non-vacuous? How can ceteris paribus laws be true? And how can they help in formulating successful policy interventions in a diversity of contexts? It turns out that ceteris paribus clauses are not always used legitimately. They are meant to fence off a theory from disturbing factors, but economists who do not specify the clause well enough tend to fence variables in rather than off. In such cases, it would be better to use theoretical abstraction, which is something very different from the use of ceteris paribus clauses. However, abstract theorising conceptually leads one away from the concrete detail of real world situations in which policies take place. Hence, a fourth question arises: how can policy interventions be properly designed on the basis of abstract laws? To answer this question, I defend interdisciplinarity in concept choice.
\end{abstract}

Keywords: ceteris paribus, abstraction, concretisation, logical strength, interdisciplinarity, socio-economic policy

JEL Classification: A12, B41, Z18

In many sciences it is necessary to model the workings of causally related phenomena under the proviso that other variables than the ones under investigation are constant, absent, or negligible. Scientific explanation comes with the use of ceteris paribus laws: lawlike generalisations hedged with clauses that specify under what conditions the generalisation can be expected to be applicable. In the literature

AUTHOR's NoTE: I thank two anonymous referees for their critical comments, both on content and on writing style. They have been of much help in improving this paper. 
there are roughly three approaches to the meaning and role of ceteris paribus laws. Either the ceteris paribus clause is seen as merely specifying the set of conditions under which the lawlike claim is true; or the clause specifies mere normality conditions; or the ceteris paribus laws describe the capacity (or disposition) of a system to behave in a certain way without the certainty that it will actually do so (it depends on the clause whether it will).

Without opposing any of these approaches, this paper defends five claims. First, what makes ceteris paribus claims interesting in general is the quest for truth when the ceteris paribus proviso is false. Ceteris paribus reasoning strategies only have to 'keep other things equal' when these things do not remain the same-otherwise there is no point in inserting such a proviso. This means that some form of falsity is involved when doing science and this is inherently interesting, especially for realists.

My second claim is that a ceteris paribus generalisation is always subjunctive, not indicative. Ceteris paribus laws are best seen as counterfactuals. This claim must be distinguished from the well known understanding that laws differ from accidents in that they sustain counterfactuals, as explored in a vast body of literature. The familiar idea is that laws have nomological necessity. The most recent work in this area is by Marc Lange $(2005,2009)$. The difference between my claims and Lange's is that my worry focuses on the scepticism in thinking that lawlike generalisations mean nothing in economics due to its ubiquitous use of ceteris paribus clauses. Both the metaphysics and the semantics of ceteris paribus clauses are poorly understood by many economists.

The third claim is about the use of ceteris paribus-hedged claims. In policy issues, it turns out that any ceteris paribus assertion requires a very strict resilience of the environment. The slightest difference in the distribution of helping factors in the way a policy intervention can be successful in one context tends to make a similar policy in another context unsuccessful. So the point is not that 'other things' abstain from behaving abnormally, but that they remain as stable as needed for the external validity of a policy evaluation. ${ }^{1}$

The fourth claim is that successful predictions enabling policy interventions in varying contexts require abstraction; not the recourse to

\footnotetext{
${ }^{1}$ I am grateful to an anonymous referee for noting that 'other things equal' often merely means that they do not behave in weird ways.
} 
the sort of hedging for which ceteris paribus clauses have been designed. A genuine ceteris paribus clause defines a policy relevant problem just as concretely as the description of the disturbing variables demands. So I propose that abstraction from this concrete set of situational details is needed to make policies work, but I also warn that the description of a situation may overshoot the required level of abstraction, making it useless.

The fifth claim is that we need the interdisciplinarity of social scientific work for policy purposes. Interventions necessitate the conceptual approach provided by other (social) sciences in order to reverse the abstractive process toward concrete world where the interventions actually take place.

If a clause conditions a generalisation (lawlike or not), two issues arise. One concerns truth and the other concerns vacuity. As to the first, if the condition is false, the conditional proposition will always be truewhich in turn leads to a form of (alethic) vacuity. In addition, realists like to think of economics as an enterprise that seeks truth: the habitual falsity of the ceteris paribus clause seems to be in conflict with the realist approach to a philosophy of economics. As to the second issue, in the philosophy of economics there has been a worry that generalisations fail to be empirical for the ubiquity of ceteris paribus clauses. The source of the worry is that if such clauses severely delimit the range of cases in which the generalisation can be expected to show itself, it will withstand testing. The claims of economics cease to be scientific. ${ }^{2}$ In this paper I sharply distinguish between issues of truth and of vacuity.

Given the ubiquitous use of ceteris paribus clauses, however, it seems that the assumption that ceteris paribus laws are respectable parts of scientific theories is a good starting point of any normative theory of science. ${ }^{3}$ Paul Pietrosky and Georges Rey (1995) took this as

\footnotetext{
${ }^{2}$ De Marchi has vividly described how economists of the London School of Economics tried to conform their theorising to the demands of the Popperian demarcation criterion, see De Marchi 1988. This is also one of the sources of Uskali Mäki's worry that the opinions polarise when it comes to the status of economics, see Mäki 2002.

${ }^{3}$ Already here I use two different senses of 'theory', one in object language and one in meta-language. In this paper I do not presume to have a precise concept of what a theory is-which concerns contested area. The point of the present paper neither depends on the outcome of this debate, nor does the use of the term reveal any well thought position about, for example, the semantic view of theories or the syntactic view, and so on. It suffices to view a theory as a set of hypotheses about lawlike relationships and a test hypothesis as deductively inferred from the theory under test. Of course, this approach loosely conforms to the Hempelian view of science.
} 
their starting point when they asked how the use of ceteris paribus laws could be non-vacuous. Meanwhile, of all scientists, economists turn out to be the wholesalers of ceteris paribus clauses. The question, then, is to what extent this abundant recourse to hedged laws can be defended specifically in economics. ${ }^{4}$

In this paper I argue that ceteris paribus clauses as part of lawlike statements can be defended to a very large extent. However, two things should be well considered. First, economists themselves tend to have a blurred view of what economic theories buttressed with ceteris paribus clauses precisely amount to. They often coin this 'abstraction'. Second, the question how ceteris paribus laws can be non-vacuous-Pietrosky and Rey's research question-must be well distinguished from the question how ceteris paribus laws can be true. The importance of the latter question comes to the fore as soon as it is realised that the very nature of ceteris paribus caveats stem from the trouble that other circumstances do not remain unaltered. The semantic question is this: how can deliberate insertion of falsity be functional in the quest for truth? This paper answers both questions.

To do this, I distinguish four different cases. In the first case, ceteris paribus clauses may be purely ad hoc. This is a clear case of vacuity. A ceteris paribus law is vacuous because theorists who make use of ad-hoc clauses can offer false explanations for phenomena without ever having to revise their theory in light of counterevidence. This idea is the starting point of section 1 where a distinction is observed between two types of vacuity: vacuity simpliciter and trivial truth of the ceteris paribus clause. In the second case, explained in section 2, ceteris paribus laws may be non-vacuous: if the clause represents a finite list of possible disturbances. The third case occurs when the clause aims to hedge a lawlike statement from a change in variables induced by influences from within the system under study. We will see an example in section 3. Now the ceteris paribus law is inconsistent due to the fact that the items constitutive of the clause are not external

\footnotetext{
${ }^{4}$ Like theories, laws bring us in contested area. In my view lawlike statements merely describe causal connections that inform us that similar cases as the one under study may occur in the future. Among natural scientists it is normal to speak of (natural) laws as being more fundamental than any causal claims in the special sciences. Quite apart from the as yet unsettled question whether physicists really discover (fundamental) laws, I doubt that there are any such laws in social science. The answer to this question is however of no consequence for the present paper. All I need is that it makes sense to more modestly speak of 'lawlikeness' in social science. When I use the term 'law' as well as when I use 'lawlike statement', I refer to nothing else.
} 
to the thing that falls under the description of the very lawlike statement that was to be hedged. The fourth case again allows the ceteris paribus law to be non-vacuous, but now along different lines. Pietrosky and Rey have proposed that if violations of the clause can be explained by a theory independently from the law in question, there is no case of vacuity. In section 4, I will use their approach to argue that interdisciplinarity matters in a non-trivial way.

From this point I move, in section 5, toward very different but related epistemic operations in economics: abstraction and concretisation. We will see that Pietrosky and Rey's condition seems to deal with abstraction rather than with the use of ceteris paribus clauses. Issues of the truth value of a lawlike proposition resting on a hedging strategy drive a familiar debate: about how false clauses can make such laws true. Section 6 provides an answer that I think is not often heard: ceteris paribus laws are counterfactuals. Next, section 7 discusses how abstraction relates to the quest for truth. Finally, armoured with these concepts-abstraction, concretisation, and counterfactuals-in section 8 , I will defend interdisciplinarity of social research from a new point of view.

Throughout the paper, I assume without discussion that the differences between using ceteris paribus clauses and theoretical abstraction apply to science in general. However, when it comes to policy, I focus on social science specifically. In special cases, such as when considering the sloppy distinctions often made between various isolation techniques, I take economics as a paradigm case.

\section{TWO SENSES OF THE VACUITY OF CETERIS PARIBUS LAWS}

Why would anyone want to dismiss the use of ceteris paribus clauses if it is ubiquitous in scientific practice? Because theories that aim to explain the workings of the world must be subjected to test and any hypotheses furnished with caveats escape falsification. Such hypotheses are empirically empty. This view is puzzling. Do we dismiss all economic science as empirically empty?

Ceteris paribus clauses express the requirement that circumstances, external to the ones that are subject to the explanatory theory, are stable; only the variables under investigation are supposed to change. When any one of the circumstances to which the clause refers does change, the test itself fails, not the hypothesis under test. Ceteris paribus clauses immunise hypotheses-and with them the theories to 
which they belong-from falsification. Daniel Hausman has phrased this as 'ceteris paribus, everything that is F is G'. F-things that turn out not to be $\mathrm{G}$ do not contradict this claim, however, if the cetera (that we can blame are not paria) have been chosen in a non ad hoc way (see Hausman 1992, 139-142).

\section{Vacuity simpliciter and falsity as two types of vacuity}

Demand responds negatively to changes in the price of the good demanded, except when it fails to do this (e.g., because incomes change). Interest rates rise when capital turns scarcer, except when they happen to drop, or do nothing (because a slump crushes investors' appetite). Complaints about economic predictions are now that they are wrong, then that they are inherently untestable. ${ }^{5}$ But is it not equally true that physicists are happy to talk of planets that move in ellipses around the sun except when they do not (because gravitational forces of other planets deform the ellipse)?

We need a good story to explain this. The trouble is not merely that we hope theories to be rigorous or strong. If ceteris paribus laws are immune to counterexamples they are also meaningless. There is little point in saying that 'every F-thing has the property $\mathrm{G}$ except when this is not the case'. An entire canonical literature tries to find ways to circumvent the vacuity. ${ }^{6}$ As Pietrosky and Rey put it, clauses are vacuous unless it is specified when the cetera are paria, and such a specification is hard to come by. They even speak of a panic that they want to quell (Pietrosky and Rey 1995, 82). And their answer is at least partly convincing: very loosely said, a scientist has to make sure that the ceteris paribus clause cites factors that can be explained with theories independent from the theory the putative ceteris paribus law has been derived from. ${ }^{7}$

I believe it is important to distinguish problems of mere vacuity due to the inherent resistance to testing from problems of truth. While ceteris paribus laws run the apparent risk of developing into immunisation strategies, a separate matter is that they must have truth

\footnotetext{
${ }^{5}$ Note that this is not the same as resistance to testing due to inferential, technical, practical, or ethical obstacles.

${ }^{6}$ The list of authors who more or less implicitly wrote about ceteris paribus seems endless. Apart from Hausman and the above mentioned Pietrosky and Rey, other authors have explicitly been dealing with ceteris paribus. See, e.g., Cartwright 2001; Mäki 1994; Niiniluoto 2002; and Nowak 1989.

${ }_{7}$ They elaborate on it much more rigorously and precisely. Section 4 below will do much more justice to their proposal.
} 
value. Note that a common approach to ceteris paribus laws is to formalize them into material implications ('ceteris paribus, if it is an $\mathrm{F}$, then it is a G') and these are the weakest kind of implications in logic. Clearly, it only requires falsity of the antecedent to make the entire conditional true. Integration of the clause into the antecedent is enough to show that, if (and only if) formalised in this way, all ceteris paribus laws are trivially true. So in sum, we have two issues at stake here: non-falsifiability and trivial truth. One is the issue of vacuity connected to immunisation; the other is lack of degrees of freedom of the truth function. I will label the first 'vacuity type 1' and the second 'vacuity type 2'.

There is a second argument for addressing the issue of truth. Social (or economic) theory has the obvious pretention to be useful for social (economic) policy. As I have set out to explain elsewhere (Rol and Cartwright 2012), without true lawlike claims inferred from explanatory social theories, the use of policy recommendations cannot be warranted either.

Pietrosky and Rey's quest concern vacuity type 1 . Their starting point is, like mine, that ceteris paribus laws can be respectable parts of scientific theories in general. My other additional presumptions are that for economics such laws are equally acceptable even though it has been thought dubious that economic theory seems to be swamped in them; and that the related problem of vacuity type 2 deserves treatment independently of the problem of vacuity type 1 . The answer to both questions-how ceteris paribus laws can be non-vacuous and how they can be true-leads to the same conclusion.

\section{TYPE 1 VACUITY: HOW TO FENCE OFF THE EXPLANANDUM}

A ceteris paribus law is a lawlike statement hedged with a clause. This clause reports exceptions to the lawlike statement. One obvious way to warrant a ceteris paribus law to be non-vacuous is by making the clause manageable, i.e., finite. This describes the second possibility listed in the introduction. If the finite set of possible exceptions to a lawlike statement is put forward before the test, both the phenomena and the test hypothesis can be saved. All that has to be proved is that one of the proposed exceptions applies. So both a judgement is needed about what exceptions are permissible and a guarantee is needed that this judgement precedes actual testing. 


\section{Finite ceteris paribus clauses and nomological machines}

For instance, all first year economics textbooks sum up three possible exceptions to the rule that demand negatively correlates with price (let us call this 'the law of demand'): permissible exceptions apply when (disposable) incomes of demanders change, when prices of substitutes or complements alter, and when preferences vary. The ceteris paribus clause says that these possible changes are not to occur for the law to be strictly true, but the very reason why anyone would use a clause like this is that these changes do occur. If they did not, there would be little point in constructing the clause.

So testing the law happens under the caveat that it is not strictly true, because the clause may be violated. There may be no correlation between price and demand or after a price increase rising demand may even follow, reversing the law of demand. If the agents whose behaviour is investigated enjoyed a substantial pay increase after which they raised demand for almost everything, they will also increase demand for the good under investigation even when it turned more expensive. In the modelling practice we say that the demand line has shifted to the right. Only if it can be shown that incomes did in fact rise (or that either of the other two items on the list did not remain the same) we continue to accept the lawlike statement as true. Thus, the law of demand is saved even in an unsteady world. So in sum, falsifying instances must first be confronted with the ceteris paribus clause. In order to do so, this clause must be finite. If this is the case-provided the appropriate procedures are in place-a ceteris paribus law is not vacuous.

John Maynard Keynes noted in The general theory of employment, interest and money how important a well specified (i.e., finite) ceteris paribus clause is. After an exposition of how the relation between the 'rate of consumption' and aggregate income changes due to changes in the marginal rate of consumption-a possibility the classical economists had disregarded-he warns for the 'extreme complexity' of the model:

[...] these seem to be the factors which it is useful and convenient to isolate. If we examine any actual problem along the lines of the above schematism, we shall find it more manageable; and our practical intuition (which can take account of a more detailed complex of facts than can be treated on general principles) will be offered a less intractable material upon which to work (Keynes 1973 [1936], 249). 
The classical model, according to Keynes, implicitly presumes the marginal propensities to consume and to save as constant. The possibility of changes in this 'rate of consumption' made possible by for instance the banking system or simply by the degrees of freedom that exist in the allocation of the budget went unnoticed by the classical economists. However, it seems 'to be useful and convenient to isolate' this aspect of economic life, as long as you realise that such a procedure involves a deliberate isolation. A finite list makes the subject matter concrete, because every interfering factor is accounted for.

The role of well specified clauses becomes clear if we consider laboratory practice. In the natural sciences, both explanatory research as well as the testing of hypotheses takes place in an engineered setting more often than is possible in social science. ${ }^{8}$ The law under investigation is never investigated 'in the wild'; many provisions have to be made. All sorts of helping factors-clean glasswork in chemistry, well specified rules for subjects in behavioural economics-must be in place. Also, interfering factors preventing the phenomenon searched have to be absent, like friction. The design of a laboratory setting implies the subjection of reality to the will of the researcher. It is a model world with stable (enough) preconditions. In a fall experiment the conditions of the ceteris paribus clause can be mimicked by a near vacuum. Thus, the feather will drop with the same acceleration as a pebble. A test of the law of free fall requires that a model reality is created in which the ceteris paribus clause is made true. ${ }^{9}$ In other words, a laboratory is a world where the ceteris paribus clause applies; it is a 'nomological machine', as it has been dubbed by Nancy Cartwright (see, e.g., Cartwright 2001). ${ }^{10}$

Note that ceteris paribus clauses do not alter the level of abstraction of the laws that they hedge. This is what brought Uskali Mäki to introduce the term 'horizontal isolation'." I have often noticed-in

\footnotetext{
${ }^{8}$ Of the behavioural sciences, social psychologists make use of a kind of laboratory most frequently. For a nice controlled experiment, see Alter, et al. 2007.

${ }^{9}$ Even though a perfect vacuum cannot physically be created; but natural scientists are content with an approximate approach.

${ }^{10}$ Nancy Cartwright stresses that any phenomenon, triggered by human intervention or natural, is in fact the nomological machine at work. Her point is that (fundamental) laws never work in isolation of helping factors, due to which no laws of physics describe reality; they 'lie', see Cartwright 1983.

${ }^{11}$ Uskali Mäki's idea is that summing up details to be excluded at the same level of abstraction amounts to isolating sideways, or horizontally, one set of details from another. Abstraction would then be vertical in the sense that we derive concepts without reference to the detail of actual economic processes. See, e.g., Mäki 1994.
} 
personal communication with economists-that they tend to forget this important point: abstracting from the world requires a choice of some properties out of many and labelling these as important for further scrutiny and theorising; in contrast, hedging requires reference to all properties, especially to those that you do not want to study.

Incomes, preferences and prices of competing goods must all remain stable for the law of demand to express itself in the data, so only the relationship between price and quantity demanded seems to matter. But the formulation of the clause reveals that we have to constantly focus on the details in it to make things happen, instead of on the price-demand relationship itself. A ceteris paribus clause anchors in the concrete world. But theorising involves a movement away from this world. It brings the economist from my erratic demand behaviour toward abstract concepts like 'demand', 'productivity', and 'inflation'. In consequence, the epistemic role of abstraction is very different from that of a ceteris paribus clause.

\section{SYSTEM EFFECTS FEEDING BACK: HOW TO FENCE IN THE EXPLANANDUM}

What if a price drop increases the budget of demanders, causing an increased appetite for a substitute, rather than for the cheaper good? This may happen even with stable independent preferences and stable income earnings-that is, even when none of the cetera stipulated in the clause is violated. Now demand drops as a response to a price decrease. We know that another lawlike statement can provide for an explanation here, about differences in the rate of diminishing marginal demand with rising disposable income. ${ }^{12}$ Here we have a case of the well known Giffen goods, also known as goods with perverse demand behaviour. It is important to note that the budget is raised by the very price drop itself, not by external influences. System effects of the working of the law feed back. As the ceteris paribus clause aims to merely fence off external influences, that is, external to the particular causal connection described by the lawlike statement, the conclusion must be that we cannot refer to the expansion of the budget due to rising purchasing power in a ceteris paribus clause in a case of Giffen goods. Counter the more traditional microeconomic approach, I claim that ceteris paribus caveats do not apply to a change in variables induced by the very

Below I do however not follow his nomenclature entirely. Elsewhere I use 'idealisation' for horizontal isolation, see Rol 2008.

${ }^{12}$ This famously is Gossen's law. 
lawlike behaviour under study, because such an admonition would be inconsistent.

Another example of this case would be the famous Lucas-critique: changes in parameters of a model cannot coherently be fenced off if the model also assumes that people are capable of learning. Once again a model uses an assumption that feeds back into the system, whereby isolation of its effect turns inherently contradictory.

Keynes, quoted above to show the importance of a finalisation of the clause, now shows us the importance of system feedback effects:

\begin{abstract}
Now, in so far as the classical theory assumes that real wages are always equal to the marginal disutility of labour and that the latter increases when employment increases, so that the labour supply will fall off, cet. par., if real wages are reduced, it is assuming that in practice it is impossible to increase expenditure in terms of wageunit. If this were true, the concept of elasticity of employment ${ }^{13}$ would have no field of application. Moreover, it would in this event, be impossible to increase employment by increasing expenditure in terms of money; for money-wages would rise proportionally to the increased money expenditure so that there would be no increase of expenditure in terms of wage-units and consequently no increase in employment. But if the classical assumption does not hold good, ${ }^{14}$ it will be possible to increase employment by increasing expenditure in terms of money until real wages have fallen to equality with the marginal disutility of labour, at which point there will, by definition, be full employment (Keynes 1973 [1936], 284).
\end{abstract}

The trouble Keynes draws our attention to in this quote is that the classical economists presume equilibrium as a result of the confrontation of labour demand and labour supply, but disregard that such an equilibrium must be reached dynamically from any position of disequilibrium. For 'elasticity of employment' to have any meaning at all, we must all but presume that demand for goods can change even when real wages do not, for instance by increased lending. After all, for a rise in employment due to increasing demand, someone must start demanding more. But the classical economists end up analysing such an increased appetite as having no effect because money

\footnotetext{
${ }^{13}$ In The general theory the elasticity of employment is the relative change of employment opportunities resulting from a relative change in demand for industrial produce.

${ }^{14}$ Keynes refers to what he calls 'the second fundamental postulate' of the classical theory of employment. It is an equilibrium condition, which says that the real wage is equal to the marginal disutility of labour for the employee.
} 
wages (as opposed to real wages) will fall. All of these factors, such as changing preferences and propensities to consume and save, are kept in an ideal stable position.

Keynes's The general theory basically warns that some cetera cannot be fenced off in a clause without violation of the implicit assumptions of the very theory that puts the ceteris paribus clause in place. In other words, sometimes the ceteris paribus clause is incoherent and the theory of employment as proposed by the classical economists, Keynes tells us, is a case in point. My claim, then, is that Keynes's point against the microeconomics of his time is similar to the Giffen goods example in the relevant respect. It is fine that the ceteris paribus clause sometimes fences off variables but not when these variables form essential parts of the system studied.

An insufficiently well developed insight into what a model of a system under study entails leads to incoherence. The ceteris paribus clause must not be inherently denied by the other assumptions of the theory. Therefore, a theory about a small system can bear a more extensive ceteris paribus clause than one about the same phenomena but studied as a larger system (including more phenomena). To push things further, a consistent dreamed-of 'theory of everything' can have no ceteris paribus clauses at all; but then again, fortunately, it does not need one either. So the question is of course how big we assume the system to be. In partial analysis we consider very small systems, like single markets. General equilibrium theory is trickier. ${ }^{15}$

We now see that ceteris paribus laws fence off disturbing phenomena while the inevitable phenomena-in the Keynes example, in the Lucas critique, or in the Giffen goods example-are rather to be fenced in. In such a case, the problem is not of vacuity, but of inconsistency.

\section{THE NEED FOR A LOGICALLY INDEPENDENT EXPLANANS}

The law of demand predicts a correlation between price and quantity demanded only under the caveat specified. The design of a finite ceteris paribus clause requires prior understanding of all helping factors of a causal process that leads to a particular configuration of phenomena. But what factors are relevant to do the hedging? Scientific research

\footnotetext{
${ }^{15}$ I believe that one of the causes due to which macroeconomics often poses perplexing difficulties in specifying its conceptual apparatus is that there is little recourse to ceteris paribus clauses.
} 
implies a lack of knowledge, not a surplus. In curiosity driven investigation we enter partially new terrain. Hence we typically do not know enough to design well specified clauses. Now, the use of ceteris paribus runs the risk of vacuity and economics is vulnerable to such criticism because its clauses are typically open. Indeed, economics is a science where the unspecified ceteris paribus clause is in extensive use. And this is true, if only to a lesser extent, of other sciences. Thus, Pietrosky and Rey note that "cp-clauses are needed in science precisely when it is not clear what the 'other things' are" (Pietrosky and Rey 1995, 87). ${ }^{16}$ So the problem is that open or infinite ceteris paribus clauses leave unclear how many and which of the variables are to remain constant. How should one conceive of non-vacuous ceteris paribus laws in economics and in other social sciences?

Pietrosky and Rey seek a sufficient condition for a ceteris paribus law not to be vacuous. Modest as this objective may seem, their result is sophisticated: the ceteris paribus clause is a condition yet to be specified by the scientist, but specifiable in non-question begging terms. Now, conditions can be 'C-normal' or 'C-abnormal'. ${ }^{17}$ "So the task is to find a characterization of C-normalcy that avoids this charge [of vacuity]" (Pietrosky and Rey 1995, 88). This is the trick that does it:

Metaphorically: cp-clauses are cheques written on the bank of independent theories. These cheques represent a 'promise' to the effect that all C-abnormal instances of the putative law in question can be explained by citing factors that are [...] independent of that law. If the promise cannot be kept, the cheque was no good to begin with. Or, in terms of a more traditional metaphor long associated with cp-laws: a cp law holds only in a 'closed system', i.e., a system considered in abstraction from other, independently existing factors (Pietrosky and Rey 1995, 89).

And, one has to observe:

Our requirement that factors be 'independent' is intended to exclude factors whose only explanatory role is to save a proposed ceteris paribus-law (Pietrosky and Rey 1995, 90).

In sum, Pietrosky and Rey try to avoid vacuity by claiming that ceteris paribus laws are permitted provided that either the clauses

\footnotetext{
${ }^{16}$ Emphasis theirs. The extent of the problem is implied by the title of section 1.3 of their paper, where they note this: "A problem not only for special sciences".

${ }^{17} \mathrm{C}$ is the yet-to-be specified condition. See Pietrosky and Rey 1995, 88.
} 
specify interfering factors in a finite way or if the scientist uses the available evidence to include independent factors that explain an apparent interference. Thus, the crucial factor is the possibility of producing convincing evidence, perhaps in the future, in light of the requirement that such purported evidence is independent from the law. Here we have the fourth case from the list.

\section{Three cases of non-vacuity}

We speak of 'disturbing factors' when a phenomenon contradicts a lawlike regularity. The regularity has its exceptions and the phenomenon-e.g., rising demand with rising prices-needs an explanation. If the phenomenon is a disturbing factor this means that it cannot be explained by the theory that produces the lawlike regularity. The explanandum is seeking an explanans.

The scheme below summarises three possibilities for non-vacuity. In the first column we find the three cases of non-vacuity as mentioned in the introduction. (Note that the table does not list case number 1the case of the ad hoc clause, which was one of vacuity.)

Table 1

\begin{tabular}{|c|l|l|l|}
\hline \multicolumn{3}{|c|}{ Ways to non-vacuously deal with a closure regarding phenomenon ph } \\
\hline $\begin{array}{c}\text { 岁 } \\
\Xi\end{array}$ & \multicolumn{1}{|c|}{ Explanans } & \multicolumn{1}{c|}{ Explanandum } & \multicolumn{1}{c|}{ Epistemic operation } \\
\hline 2 & isolating clause violated & ph is a disturbance & idealisation, fencing off \\
\hline 3 & theory about system & ph instantiates own theory & explanation, fencing in \\
\hline 4 & $\begin{array}{l}\text { other, independent } \\
\text { theory }\end{array}$ & $\begin{array}{l}\text { ph instantiates other } \\
\text { theory }\end{array}$ & abstraction \\
\hline
\end{tabular}

The regularity was hedged, it was part of a closure, so if it can be shown that the hedging clause was somehow violated due to the particular disturbing phenomenon, the phenomenon is explained by reference to the clause being violated. This means that the instability of the environment external to the system under study explains the disturbance. Consequently, the hypothesis expressing the lawlike regularity is saved. This is shown as case 2 in the table.

Case 2 is the Giffen goods one, however, and in such cases, the causal factors breaching the regularity cannot be explained with 
reference to a hedging clause because theoretical knowledge tells us that these factors will come into play whenever the regularity does. The clause would contradict the very workings of the system under study. Now there must be a more abstract theory with a wider scope, explaining the more complex regularity-e.g., talking of substitution effects and income effects and their relative weight in a causal process. Both positive and negative relationships between demand and price instantiate this theory, provided all the conditions are in place (the income effect was in fact stronger).

It is, thirdly, also possible that the theory that renders the lawlike regularity does not account for any exceptions to it. Some other theory does. If this theory is logically independent from the theory at stake, the ceteris paribus law is saved and non-vacuous if the exception can in this way be explained. Now the explanans of the phenomenon is the other theory. If this theory really is independent from the theory to which the law belongs-as Pietrosky and Rey demand-this presents a genuinely new case 4 . In the following section, I will explain why I think this a case of abstraction.

\section{BEYOND THE CETERIS PARIBUS CLAUSE: ABSTRACTION}

If the disturbance of economic regularity by variables, which we find listed in a clause, can be explained by citing particular factors that really are independent from the theory for which the clause was used, these factors will frequently reside in disciplines outside of economics. After all, the factors cannot originate in the system about which we theorise. If they did, their influence on the system studied would be part of the workings of the system. Moreover, hedging it from causal influences inherent in this system would be, as stressed above, inconsistent. So then this question turns up: how big is the system?

Economists research (models of) economic systems. Independent factors are most likely to be found, in consequence, in non-economic systems. Indeed, the sort of disturbances that challenge the ceteris paribus law do in fact often originate in domains studied by sociologists, psychologists, biologists, and others: psychological irrationality (such as cognitive dissonance or preference intransitivity), political instability, climate change, and so on. An economic system may of course also be embedded in a context that is itself economic in kind; that is, the independent factors that sustain the application of a ceteris paribus clause do admittedly perhaps originate in the economic 
discipline itself. But more often the concept of an 'external shock' refers to a factor or factors outside of the economic realm.

\section{From ceteris paribus to the role of abstraction in science}

Let us suppose that we study microcredit facilities to finance manufacture in an urban area and its effects on poverty. Economic theory predicts that better access to credit reduces poverty due to new possibilities for poor families to set up a small business. What is more, the theory predicts that this effect will turn up in New Delhi just as well as in London, and in the urban locality under study with respect to manufacture as well as in an agricultural local economy with respect to the financing of fertilizers. This means that the prediction is nothing other than the prediction of a lawlike regularity. ${ }^{18}$

But to think, as policy makers often do, that the lessons drawn in one case travel to a new case without any problem amounts to the presupposition that the institutional, sociological and psychological 'helping' factors remain the same. To assume that what we learn in one case also applies to another entails employing a ceteris paribus clause. This is tricky. If microcredit helped reduce poverty in New Delhi, will it do the same in London with its well developed financial institutions, its depth of the capital market? It is not clear that it will. And if the availability of microcredit in a densely populated city increases industriousness and family income, does it do the same in the countryside where markets are much more dispersed? Probably not, but we do not quite know what causes what. And if we did, the presumption that the effects of microcredit are the same in such diverse institutional and geographic contexts would amount to applying one and the same ceteris paribus clause equally in these different contexts. But we do not know much about all these variables that make up the context.

So if predictions on the basis of economic theory prove wrong, reference to each and every one of the independent factors is needed, for instance to the particular organisation of the local capital market or the proximity of consumer markets, in order to explain the instances that may falsify the prediction. The problem is that we need to ban any

\footnotetext{
${ }^{18}$ Note, by the way, that already the interest in microcredit shows that the institutional background is supposed to somehow matter: pure economic theory-abstracting from the role of institutions - would never distinguish between the availability of large sums of capital and microcredit financing by loans of 250 dollars. Pure economic theory would just sustain talk of 'the' capital market, not of markets that can only be told apart by reference to an institutional background.
} 
disturbing factors from the stage. This formulation uncovers our ignorance, because we do not refer to specific elements of the 'other circumstances', our research is just troubled by the richness of the context in which the cited economic mechanism is supposed to work. We are, in other words, not capable of explicating a finite ceteris paribus clause. If we could list all the relevant background causal powers supposing to co-determine the success of our policies, we would have a road map towards non-vacuous immunisation of our prediction. We would have a ceteris paribus clause. Alas, we cannot.

We somehow want to say that microcredit boosts entrepreneurship because we believe that it mobilizes idle resources, unless counteracted by external factors. But this is an abstraction. It is an abstraction because it is an approach that focuses on a particular causal chain with no reference to any other causal mechanisms than the one cited by the economic theory we happen to employ. Again, this is not because we have a clear insight into what causal factors may alter the direction of events-due to which we decide to fence these off, but because we do not have sufficient access to knowledge about the staggering complexity of the concrete world and we speculate about one of the causal pathways that appear interesting. Had we known precisely which distribution of other causal mechanisms operate, then we would have little left over to research. The reader can now see that a ceteris paribus clause requires a lot of knowledge beforehand. It requires the research to already have been done.

An example from physics may further explain the point I am making. When Boyle investigated the gas laws, he was only interested in an empirical relationship between volume and pressure. The more than a century younger ideal gas law, in contrast, also relates temperature in addition to volume and pressure. In formulating his laws Boyle could not put temperature in a ceteris paribus clause, because he was not aware of the more complex relation between the three magnitudes. ${ }^{19}$ Instead he had abstracted from temperature, just as he had abstracted from variations in the weather or possible elasticity of the gas container. Abstraction is the exclusion of (the influence of) objects, their properties, and the phenomena these objects take part in, in a nonexplicit way. If the exclusion were explicit, it could not be abstraction;

\footnotetext{
${ }^{19}$ Boyle's relationship holds on an isothermal, which is of course paribus. Yet another century later, in 1873, van der Waals also entered the attraction and spatial extension of the molecules, generalising the law to liquids. Boyle could never have provided for a clause to deal with these influences.
} 
using these concepts in the way stipulated above, it would be idealisation. If isolations must be well laid-out, a prior understanding of a lot of concrete detail is required. The specification of ceteris paribus clauses is only possible after the research is done, not before.

Abstraction is a mode of reasoning that transcends a particular level of concrete detail. It is what scientists do when they focus on an apparent causal power in the belief that the world has causal structure and that the study of the causal power in question helps understanding this world. Thus, scientists know that any phenomenon is driven by a jungle of causal powers, but it makes sense to focus on one mechanism which-to the researcher-seems to make the difference. So could Boyle not better have researched the relationship between temperature and pressure in stead of volume and pressure? Or should he have studied the pressure of the atmosphere and the pressure of the gases in the container? What pattern is essential and which ones possess superfluous detail?

Clearly, the creativity of the scientist remains a mysterious process. The generation of causal hypotheses is a speculative business and the trick for any scientist is to abstract well.

\section{Economics needs the social sciences}

Now consider the following. The success of policies depends on the application of socio-economic knowledge. But even if we had a social theory so strong as to give a universal pattern in social life, this theory would not teach much about the concrete detail that becomes relevant for policy recommendations. This is because such an implementation requires knowledge of the way in which the policy is going to work out in practice. As every new context provides the policy maker with a new distribution of the factors that are to help the policy to be successful, it is unclear how the purely theoretical knowledge has to be supplemented with information about the relevant facts of the situation given.

In comparison, take the Newtonian motion laws that do describe a universal pattern. To calculate the effect of friction also involves knowledge of the specific properties of the substance that causes the friction; the quantified outcome of the motion laws will be different in a swimming pool than in the air. So to apply knowledge in the abstract a reasoning mode inverse to abstraction is needed: let us call this concretisation. Detail of a target situation has to be introduced into the corpus of knowledge that had been abstracted from study situations. 
So scientists solve two puzzles: theorising requires selecting the right focal points of interest by an operation called abstraction, application of abstract knowledge requires the insertion of the relevant details of the target situation.

The first puzzle is how to help science progress by abstracting fruitfully. The second puzzle is how to apply what we learned. The last row in the table above shows that abstraction in one discipline (say, pure economics) leaves some concrete aspects of the world (say, concerning institutions) aside. These concrete aspects neglected by the first discipline have to turn into objects of explanation by one or more other disciplines (e.g., institutional economics, anthropology, and the like). Interdisciplinary knowledge builds the more informed picture. ${ }^{20}$ For effective policy, economics needs the other social sciences.

\section{TYPE $\mathbf{2}$ VACUITY: HOW CAN CETERIS PARIBUS LAWS BE TRUE?}

I started out observing that the issue of vacuity concerns two distinct problems, one about ceteris paribus laws being empirically empty (vacuity type 1) and one about such laws being true (vacuity type 2 ). So far I developed the argument about the first problem. This section deals with the second.

\section{The logic of ceteris paribus}

A ceteris paribus clause describes a state of the world which is possible, not actual. This must be the case because it says that things do not change. Only if potentially disturbing variables do in fact, i.e., in the actual world-exert their causal influence do we really need such a clause: they are false as a description of the actual world whenever we need them. Otherwise we could abstain from using them. So what about the truth of ceteris paribus laws? I can see only two strategies to answer this question. The first is to conceptualise ceteris paribus laws as material if-then implications. The second is to understand them as counterfactual if-then phrases. I believe that only the second strategy is feasible. The reason for this is that material implications are logically too weak. After all, if the antecedent of a material implication is false, the entire conditional is trivially true.

\footnotetext{
${ }^{20}$ Whether this picture is informed enough for effective policy depends on, among other things, the level of abstraction neither being too high, nor too low. For an elaborate analysis of why policies often go wrong, see Rol and Cartwright 2012.
} 
Let us look more closely at the logical form of a material implication. All an 'if $\mathrm{P}$ then $\mathrm{Q}$ ' sentence claims is that 'if not $Q$ then not $P$ '. The ceteris paribus clause is the condition, or the antecedent of the conditional claim. So considering the law of demand and the possible disturbing influence of incomes and the number of demanders, we get a construction like 'if ceteris paribus the incomes and number of demanders, rising prices decrease quantity demanded'. But then all we end up with is 'if rising prices did not come with falling demand, then apparently the ceteris paribus clause was not true'. This is the logical form of the immunisation that Pietrosky and Rey were bothered by. Meanwhile, with a false ceteris paribus clause in the antecedent the conditional sentence if the conditions hold, then the relationship between price and demand holds' can only be true. So now the lawlike expression is trivially true. This is an unattractive result. So we are faced with the trouble that, if a ceteris paribus law is a material implication, it turns semantically vacuous even if we can think of ways to test it.

Even without a solution-which I claim lies in the second strategythis is interesting. So far the debate (see footnote 4 above) has been about how the falsity involved in a ceteris paribus clause can be handled by truth seekers. Realists, but also nearly all philosophical positions countering realism, such as instrumentalism, admit the need for true claims in order to implement policies successfully. ${ }^{21}$ Is this policy going to work? Yes it is. We either defend the truth of such an answer or we end up in an extremist post-modernist position without interest whether it works. I conclude that truth matters and that it should not come trivially.

My claim, then, is that ceteris paribus laws are counterfactuals. They are conditional (if-then) sentences and the antecedent of the condition is phrased as a subjunctive: 'had the ceteri been paria, the postulated regularity would turn up'. Now, mere subjunctive conditionals are silent about whether the condition is met or not. But note that ceteris paribus laws imply that the condition is not met. Therefore, the special form of such a subjunctive conditional that is at stake here is a counterfactual: a phrase about a non-actual state of the world, a world where the condition imposed is met although we know that in the actual world it is not. Semantically, one could say that

${ }^{21}$ This may be controversial. Many anti-realists tend to dismiss truth as a matter of interest. But note that I here focus on the implementation of policy. We cannot avoid an interest in truth values and alethic modalities if we want to know whether the policy worked or not. 
ceteris paribus laws describe another world than our actual world. This understanding of the use of ceteris paribus laws in science gives a crucial insight into what science does. Science explains by citing causal patterns that we expect to operate even in states of the world that, so to say 'are not'. Science teaches us how to think about possible worlds, hence its lawlike character.

\section{Possible worlds}

It is common to view laws in science as counterfactuals, with initial conditions in the antecedent. Recently, for instance, Marc Lange tried to deal with the trouble that the antecedent background conditions must always be consistent with the laws cited. It is due to this condition that these laws delimit the range of permissible states of the conditions. Thus, he saves the nomological character of the law by answering the question why did things have to come out this way as follows:

"In view of these initial conditions, things would have come out this way no matter what". The limits of what can count as "no matter what" are determined by context and [...] by some set's range of stability (Lange 2005, 427).

The previous section stressed the role of context too, but in light of successful abstraction, rather than concerning laws. Note, however, that the application of the logic of counterfactuals that I focus on here is different. Economists tend to think in terms of conditions that do or do not in fact remain the same. Ceteris paribus laws are (implicitly) seen as universal material implications that escape testing when the conditions do not conform to the clause; we have seen that this is also how Hausman treats them. In logical consequence, the problem of trivial truth looms as soon as the antecedent is false. This problem fades if the ceteris paribus clause is understood as the antecedent part of a counterfactual, quite apart from problems of the nomological character of laws (these do not form the topic of this paper).

Once we accept that ceteris paribus laws are counterfactuals, the possible-worlds semantics literature opens up. ${ }^{22}$ For my present purposes it suffices to note the following observations about the counterfactual interpretation of ceteris paribus laws.

\footnotetext{
${ }^{22}$ Kripke, Lewis, and Stalnaker have driven this literature. It takes us too far to present the logic behind counterfactuals in this paper. For an interesting analysis, see Lewis 1973.
} 
A counterfactual claim describes a state of the world that differs from the actual state of the world; it describes how reality could be. First, this is not useless. We imagine other possible states of the worldin brief, 'other worlds'-all the time. In order to avoid a crash, I drive carefully. That is, I can see what the possible world in which I do not drive carefully will bring me: a crash. To say that 'if I do not drive carefully, I will crash my car' amounts to saying that I can have positive knowledge about particular states of the world that are not actual (but possible). Note that defending the credibility of the claim does not require any explicit recourse to laws. Secondly, it makes sense to say that the counterfactual claim is true or false. The description of the possible world where we all drive carelessly, such that the claim that there would be many car crashes is true, is a non-trivial description. It enables us to derive a warning when combined with the normative claim that we should try to minimise car crashes. Finally, descriptions of possible worlds may be true of any number of the infinite set of possible worlds. (Some such descriptions may even be true of the actual world, but this would, by definition, not sustain a counterfactual claim.) The more possible worlds fall under a description, the weaker the claim is. A weaker counterfactual claim has greater extensionality over the set of possible worlds.

To repeat, my proposal is to interpret ceteris paribus laws as conditional propositions, the antecedent of which contains the ceteris paribus clause, which in turn describes a non-actual state of the world. The entire counterfactual has truth value. If the antecedent is false-and it is when we really need a ceteris paribus clause at all-the counterfactual as a whole does not turn trivially true by implication. Counterfactuals provide precisely the logical form we need to make lawlike claims.

\section{The logic of abstraction}

I have distinguished abstraction from the use of ceteris paribus propositions. Abstraction does not require any explicit fencing off, so it does not deliberately use a ceteris paribus clause. Abstraction does not necessitate a conditional. But when it comes to the truth of abstractive claims, the proposition that is being abstracted from must be true if the abstracted proposition is to be true. If 'demand relates negatively with price' is true, we can be confident that 'demand relates to price' is true. So we see here that abstraction does not use counterfactuals; its logic is 
different. While ceteris paribus laws can be true or false, abstraction is truth preserving.

This makes sense. Theories have been derived from descriptions of concrete phenomena. If the description of a phenomenon is not correct to start with, anything may happen when we theorise about it. But if the description is truthful, the theory abstracts from it and the abstracted claims that follow leave out many details. Given that all the descriptions of detail are correct, whatever is selected in the abstraction continues to be described correctly. There cannot be a loss of truth value here.

\section{THE PROBLEM OF LOGICAL WEAKNESS: REPRISE}

While some proposition may be true of many worlds, even if not of the actual world, abstraction of this proposition leads to claims that are true of more possible worlds. This is because abstraction is a process by which concrete detail is left out. The more details, the fewer the number of possible worlds that fall under the description of these details. So, conversely, a less detailed-i.e., a more abstract-description counts more possible worlds in its extension. In other words, an abstract description of the world picks out more possible states of the world from the space of possible states than a concrete description. Thus, the very simple motion laws of Newton are highly abstract: they apply to the fall of objects in my room and to the elliptical orbits of planets. Such a level of abstraction allows for many possible states. The complex and detailed description of this particular feather and how it behaves in its environment, specifying air pressure and so on, allows for fewer possible states.

\section{Abstraction and truth}

Truth is a property of propositions that refer to the actual world. A proposition is true if it correctly describes the state of the actual world; false if it does not. This I call the naïve sense of truth. Now, in possible-worlds semantics, matters of truth are more sophisticated. Counterfactuals refer to other states of the world than the actual state, so they cannot be true in the more naïve sense. But they can be true in the sophisticated sense: a true counterfactual counts at least one possible world in its extension. We say that if the ceteris paribus clause were true, demand would negatively relate to quantity demanded. And we believe that this is correct, even though in the actual world the clause is not true. 
Consequently, we have the sophisticated concept of 'being true of possible worlds', alongside the naïve concept of merely 'being true' (of the actual world). Although ceteris paribus laws tell us something about situations that are not actual, they do inform us about situations that are (or may become) actual. Consider the example I introduced above: 'ceteris paribus incomes, demand negatively relates to price'. An abstracted version of this could be: 'ceteris paribus incomes, demand has a functional relationship to price'. In a world with rising incomes, increased prices will perhaps not trigger a drop in demand. But the abstract functional relationship remains. In the case of Giffen goods, the relationship may even be positive. The more abstract proposition is true of Giffen goods too because it does not specify whether the relationship is negative or positive, while the less abstract proposition does.

This semantics answers the question of how counterfactual descriptions can be true. It also helps explain how they can be false. A counterfactual description may be judged false if the possible worlds it describes correctly are worlds where the laws of nature are different from how they are in the actual world.

\section{Vacuity looms again}

It follows that abstraction increases the extension of the proposition abstracted from. A very important property of abstracted propositions is that they are logically weaker than their more concrete counterparts. This is precisely because they exclude less. More appropriately, abstract descriptions exclude fewer worlds about which they speak falsely. This is both fortunate and a problem.

It is fortunate that abstraction more easily leads to truth (i.e., in the naïve sense: actual truth) for rather simple reasons. In order for scientific claims to have a bearing on the actual world, we better end up with propositions that are indeed true of the actual world, not just of some possible world. Also, actual policy takes place in the actual world. It has been noted above that policy recommendations are in fact predictions: if you implement policy $\mathrm{X}$, you will get result $\mathrm{Y}$. If the prediction is false, the policy will not work.

But, at the same time this could be problematic. The extent to which we can employ theoretical knowledge for the successful implementation of policy-knowledge which, for its theoretical qualities-depends on our capability to concretise the theoretical claims in the policy situation. 
And this is easier the less abstract the language in which the theoretical knowledge is formulated. Abstraction tends to lead to truth, but also to logical weakness and this in turn causes difficulty in filling in the concrete detail.

Economists have often been criticised for their alleged abstract theoretical approaches to policy issues. The idea is that too much abstraction ends up useless. I believe that this need not be the case, but it is a warning nonetheless. Irrelevance is the other form of vacuity. And again we see that logical weakness leads to claims that are true trivially.

Engineers need to fill in a lot of concrete detail when they apply physics theories. Social practitioners do so when they apply social knowledge. In policy, what has gone up (producing theoretical knowledge) must come down too (producing useful knowledge). It appears that engineers have an easier life than politicians, because the natural environment processes less information and is more stable. So especially in social science it is important not to abstract too much. Abstraction must render claims both weak enough and strong enough. They must be weak enough to apply to the actual world and strong enough to enable useful concretisation. It is no easy task to find the right level of abstraction.

\section{ECONOMICS NEEDS THE OTHER SOCIAL SCIENCES TO MAKE SENSE}

Above I cited Pietrosky and Rey who stress the need to produce evidence from independent factors. The idea was that, if scientists can point to disturbing factors independent from the lawlike generalisation that is subject to the disturbance, then the generalisation is saved from vacuity. What if the independent factors are as yet unknown? I concluded that the epistemic operation at stake here is abstraction rather than the employment of a ceteris paribus law. Is there a correct level of abstraction and if so, what is it?

If theories should neither be too weak nor too strong-neither blocking the way to concrete implementation of policies nor being insufficiently informed by theory-how strong do we want to have them? There is no algorithm available for how to choose the level of abstraction. ${ }^{23}$ If theoretical information derived in a study situation is

\footnotetext{
${ }^{23}$ Siegwart Lindenberg has proposed an interesting procedure for determining the "right" level of abstraction: the method of decreasing abstraction. It amounts to the idea that, at low levels of abstraction, too much information is processed for a
} 
to instruct us in a new concrete target situation, policy makers have to know enough of the details of the environment in which the target is embedded; and, sometimes, they do not know enough. This is because disciplinary abstraction often drives the policy. Economic policy is driven by economic insights, psychological intervention by psychological concepts; we carve up the social world along our disciplinary lines. But it is not clear that the resulting picture is entirely helpful in shaping successful policy.

Elsewhere I defended the thesis that policy fails too often due to overconfidence in the external validity of policy evaluation (Rol and Cartwright 2012). I proposed that, in order to choose the right level of abstraction, scientists need an interdisciplinary view. The idea is that theoretical knowledge provided by one discipline has to be complemented with information from another discipline, so that the helping factors that really matter spring to the eye more easily. Raising chances of success is already a lot in a world of uncertainty. In other words, one social science increases its relevance if its practitioners develop an interest in what other social disciplines have to say.

So does especially theoretical economics, because economists enjoy a more isolated position among the sciences by default than, say, sociologists. Therefore this claim is not trivial.

\section{REFERENCES}

Alter, Adam L., Daniel M. Oppenheimer, Nicholas Epley, and Rebecca N. Eyre. 2007. Overcoming intuition: metacognitive difficulty activates analytic reasoning. Journal of Experimental Psychology General, 136 (4): 569-576.

Cartwright, Nancy. 1983. How the laws of physics lie. Oxford: Oxford University Press.

Cartwright, Nancy. 2001. Ceteris paribus laws and socio-economic machines. In The economic world view: studies in the ontology of economics, ed. Uskali Mäki. Cambridge (UK): Cambridge University Press, 275-292.

De Marchi, Neil. 1988. Popper and the LSE economists. In The Popperian legacy in economics, ed. Neil De Marchi. Cambridge (UK): Cambridge University Press, 139-166.

Hausman, Daniel. 1992. The inexact and separate science of economics, Cambridge (UK): Cambridge University Press.

Keynes, John Maynard. 1973 [1936]. The general theory of employment, interest, and money. London and Basingstoke: MacMillan.

Lange, Marc. 2005. Laws and their stability. Synthese, 144 (3): 415-432.

Lange, Marc. 2009. Laws and lawmakers: science, metaphysics, and the laws of nature. Oxford: Oxford University Press.

sociologist to track down, so abstraction leads to leaner descriptions of the world under study. See Lindenberg 1990; and 1991. 
Lewis, David. 1973. Counterfactuals. Oxford: Blackwell.

Lindenberg, Siegwart. 1990. A new push in the theory of organization: a commentary on O. E. Williamson's comparison of alternative approaches to economic organization. Journal of Institutional and Theoretical Economics, 146 (1): 76-84.

Lindenberg, Siegwart. 1991. Die Methode der abnehmenden Abstraktion: Theoriegesteuerte Analyse und empirischer Gehalt. In Modellierung sozialer Prozesse, eds. Hartmut Esser, and Klaus G. Troitzsch. Bonn (GE): Informationszentrum Sozialwissenschaften, 29-78.

Mäki, Uskali. 1994. Isolation, idealization, and truth in economics. In Idealization in economics, eds. Bert Hamminga, and Neil De Marchi, special issue of Poznan Studies in the Philosophy of the Sciences and the Humanities, 38: 147-168.

Mäki, Uskali (ed.). 2002. Fact and fiction in economics: models, realism, and social construction. Cambridge (UK): Cambridge University Press.

Mayer, Thomas. 1993. Truth versus precision in economics. Aldershot (UK): Edward Elgar.

Niiniluoto, Ilkka. 1990. Theories, approximations, and idealizations. In Idealization I: general problems, eds. Jerzy Brzeziński, Francesco Coniglione, Theo A. F. Kuipers, and Leszek Nowak. Poznan Studies in the Philosophy of the Sciences and the Humanities, 16: 9-57.

Niiniluoto, Illka. 2002. Truthlikeness and economic theories. In Fact and fiction in economics: models, realism, and social construction, ed. Uskali Mäki. Cambridge (UK): Cambridge University Press, 214-228.

Nowak, Leszek. 1989. On the (idealizational) structure of economic theories. Erkenntnis, 30 (1-2): 225-246.

Pietroski, Paul, and Georges Rey. 1995. When other things aren't equal: saving ceteris paribus laws from vacuity. British Journal of the Philosophy of Science, 46 (1): 81-110.

Rol, Menno. 2008. Idealization, abstraction, and the policy relevance of economic theories. Journal of Economic Methodology, 15 (1): 69-98.

Rol, Menno, and Nancy Cartwright. 2012. Warranting the use of causal claims. Theoria. An International Journal for Theory, History, and Foundations of Science, 27 (2): 189-202. http://www.ehu.es/ojs/index.php/THEORIA/article/view/4075

Menno Rol teaches philosophy of social science at the University of Groningen, department of sociology, and didactics of economics at the centre for teacher training (ELAN) at the University of Twente, both in the Netherlands. He researches social scientific concept formation and the relationship between theory and policy.

Contact e-mail: <m.e.g.m.rol@rug.nl>

Website: <http://www.rug.nl/staff/m.e.g.m.rol/index> 